\title{
Improved Rotational Characteristics of Radar Antenna
}

\author{
by \\ M. Sanuki, S. Kimura and M. Baba \\ University of Tokyo \\ (Received December 10, 1960)
}

\begin{abstract}
A radar antenna model with a frame and a twin-rotor tail unit is experimented with regard to its rotational speed in the wind tunnel with the aim of improving its rotational characteristics. First the antenna dish alone is found rotatable in a wind once it is forced to rotate. The attachment of tail unit is very effective, increasing the rotational speed almost twice as large. Although the torque or power was not measured, a remarkable reduction in the antenna driving power can be expected for the same rotational speed. The attachment of the frame, which is designed to assist the rotation, is not promising due to its possible aerodynamic interference.
\end{abstract}

\section{Objective of the experiment}

Weather radar antennas are mostly installed without radomes in this country owing to its constructional complexity, extra price and possible radio wave attenuation. As a result, the antenna driving power is of somewhat serious nature especially in strong winds to which the scanning system is exposed. The wind power need not be resisted but rather utilized to reduce the antenna driving motor load.

\section{Experimental set-up}

An antenna model is constructed of a thin aluminum sheet as illustrated in Fig. 1. The antenna dish is formed according to the typical radar antenna parabolas that were employed in the past in this country with $150 \mathrm{~mm}$ diameter and $30 \mathrm{~mm}$ depth. The dish profile is nearly spherical to facilitate fabrication, which fact does not matter so much for this experiment. Around the dish a frame with the same depth and elliptical frontal area of 1.5 times the dish is attached. The frame section is designed to generate some aerodynamic torque as shown in Fig. 1 bottom right plan, forming an air scoop at the left half front and another at the right half back, thus a clockwise aerodynamic torque being obtained around the vertical shaft. Further the tail unit consists of twin semi-cylindrical rotors of $38 \mathrm{~mm}$ in diameter and $150 \mathrm{~mm}$ in length. The tail unit is, in the absence of the dish frame, well within the sweeping radius of the antenna dish and needs no extra space when rotated. The antenna dish would not interfere, in the absence of the dish frame, 


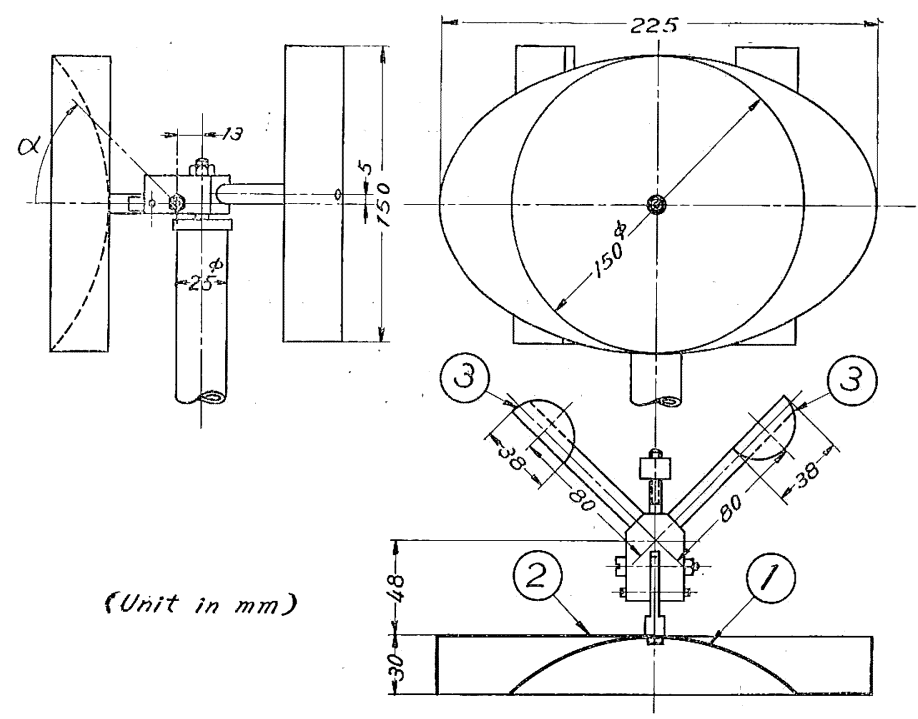

Fig. 1. Model antenna arrangement.
1. Antenna dish
2. Frame
3. Tail unit

with the tail unit up to $90^{\circ}$ elevation angle $(\alpha)$ if either the antenna dish were slightly nearer or the tail unit farther than illustrated. Both ends of the semicylinder are closed. An adjustable counter-weight is provided at the rear of the boss to attain balance. The antenna dish elevation angle $(\alpha)$ is varied as $0^{\circ}, 22.5^{\circ}$ and $45^{\circ}$, the tail rotors remaining always vertical. The rotational speed is measured by means of an electric contact provided at the shaft and a cathode ray tube oscilloscope. The experiment is conducted in the $1.5 \mathrm{~m}$ wind tunnel of the Meteorological Research Institute, Japan Meteorological Agency.

\section{Discussion of the results}

In Fig. 2 the rotational speed $N$ r.p.m. of the antenna dish alone is given against the wind speed $V \mathrm{~m} / \mathrm{s}$ for $\alpha=0^{\circ}$ and $22.5^{\circ}$. With a perfect head wind the dish did not want to go unless it is forced to rotate. With a side-wind the start was possible and the sense of rotation is entirely determined by that of the initial rotation. Below $V=7.5 \mathrm{~m} / \mathrm{s}$ the forced rotation decays after a while. But once it starts above $V=7.5 \mathrm{~m} / \mathrm{s}$, a steady ratation is possible. For this steady rotation, however, a certain amount of angular momentum might be necessary to counteract the adverse aerodynamic torque on the advancing side.

In Fig. 3 similar relation is shown for the antenna dish plus tail unit. Almost twice as large rotational speed is obtained by the attachment of the tail rotors. The torque or power was not measured but a remarkable reduction in the antenna driving power of the order of $1 / 8$ (cubic power rule) to $1 / 4$ (square power rule) can be expected. Some $5 \%$ rotational decrease per $15^{\circ}$ antenna elevation angle $(\alpha)$ is also observed up to $\alpha=45^{\circ}$. 


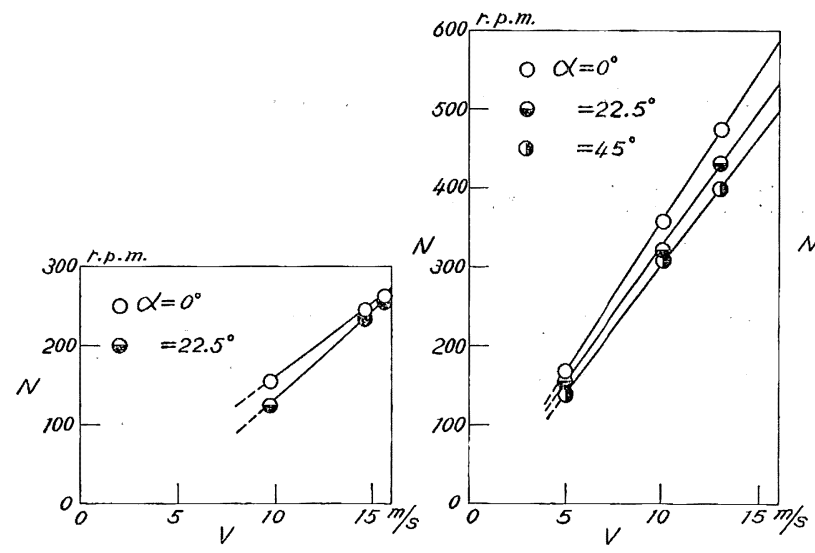

Fig. 2. Rotational speed $N$ versus wind speed $V$ for antenna dish alone $(\alpha=$ antenna elevation angle).
Fig. 3. Rotational speed $N$ versus wind speed $V$ for antenna dish plus tail unit.

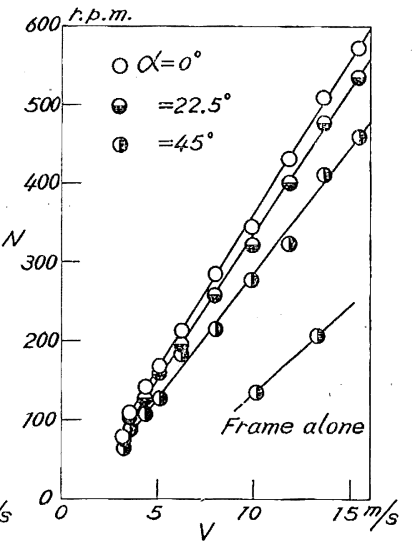

Fig. 4. Rotational speed $N$ versus wind speed $V$ for antenna dish plus frame and tail unit.

Fig. 4 gives the results for the full set of antenna dish plus the frame and tail unit. Almost no gain is attained with the attachment of the dish frame, and for $\alpha=45^{\circ}$ it even deteriorates the performance. The rotational speed of the frame alone is drawn in the figure which shows the case of $\alpha=45^{\circ}$. For $\alpha=0^{\circ}$ and $22.5^{\circ}$ the frame did not rotate at any wind speed even if forced to do so. A certain aerodynamic interference might be present with the introduction of the frame which decreases the torque for $\alpha=45^{\circ}$. Therefore the dish frame can be dispensed with.

If the antenna is required to stop its rotation in strong winds for some reasons, for instance, a system trouble, the best way will be to raise the dish up to an elevation angle of $90^{\circ}$. Otherwise a brake might be needed.

The present model is scaled down nearly to $1 / 20$ of the actual size and the actual rotational speed is of the order of $1 / 20$, too, as the linear rotational speed is effective for a given wind speed.

\section{Conclusions}

1) The antenna dish alone is rotatable spontaneously in the wind.

2) The tail unit assists the antenna rotation very much, probably much more than needed with the experimented tail area of $(38 \times 150 \times 2)+\left(\pi \times 150^{2} / 4\right)=0.65$ times the dish area. The tail area will be reduced as necessary.

3) The dish frame is not effective and can be dispensed with. 


\title{
レーダーアンテナ回転特性の向上
}

\author{
佐貫亦男・木村 茂・馬場素生
}

レーダー用アンテナ模型の風洞実巸化より回転を助けるための尾翼をつけるときは, 回転速度がアンテ ナ単独の場合の 2 倍となり，回轱速度を一定とすれば，アンテナ駆形動力芝著じるしく軽減できることを知 つた。な抽，アンアナだけでも，風の中では一度回転を始めると回転を持続する性質がある。 